\title{
Risk factors for multidrug resistant tuberculosis patients in Amhara
}

\section{National Regional State.}

Wondemagegn Mulu¹, Daniel Mekonnen ${ }^{1}$, Mulat Yimer ${ }^{1}$, Aschalew Admassu², Bayeh Abera

1. Department of Medical Microbiology, Immunology and Parasitology, College of Medicine and Health Sciences, Bahir Dar University, Ethiopia

2. Department of Regional Mycobacteriology Laboratory, Bahir Dar Regional Health Research Laboratory Center, Bahir Dar, Ethiopia

\section{Abstract}

Background: Multidrug resistant tuberculosis(MDR-TB) is becoming a major threat to tuberculosis control programs in

Backgrou

Objectives: To determine risk factors of MDR-TB patients in Amhara National Regional State, Ethiopia.

Methods: Case-control study was conducted from May 2013 to January 2014. Resistance to rifampicin and isoniazid were done molecularly using line probe assay. TB patients infected with MDR-M.tuberculosis and non MDR-M.tuberculosis strain were considered as cases and controls, respectively. Data was collected using structured questionnaire with face to face interview. Patients' clinical record review was also done.Multivariate analysis was computed to determine the risk factors of MDR-TB.

Results: A total of 153 MDR-TB and equal number of non MDR-TB patients' participated in the study. Patients who had $\mathrm{TB}$ treatment failure $(\mathrm{AOR}=13.5, \mathrm{CI}=2.69-70)$, cavitations on chest $\mathrm{x}$-ray $(\mathrm{AOR}=1.9, \mathrm{CI}=1.1-3.38)$ and contact with MDR-TB patients (AOR=1.4,CI=0.19-0.39) were more likely to be MDR-TB patients. Low monthly income $(\mathrm{AOR}=1.1, \mathrm{CI}=0.34-0.47)$ alcolition $(\mathrm{AOR}=1.5, \mathrm{CI}=0.2-0.98)$ and young age $(\mathrm{AOR}=2.9, \mathrm{CI}=1.07-7.68)$ were the AOR $=1.1, \mathrm{CI}=0.34-0.47)$,alcol
other risk factors of MDR-TB.

Other risk factors of MDR-TB. Conclusions: TB treatment failure, cavitation on chest X-ray, contact with MDR-TB patients and low socioeconomic status
were important risk factors for development of MDR-TB. Therefore, strict adherence to directly observed therapy, appropriate management of TB patients and advice on the value of nutrients are helpful to control the spreading of MDR-TB. Key words: Risk factors, MDR-TB, Ethiopia.

DOI: http://dx.doi.org/10.4314/ahs.v15i2.9

\section{Introduction}

Drug resistance is a major threat to tuberculosis (TB) control programs worldwide ${ }^{1}$. Multidrug resistant TB (MDR-TB) is defined as a simultaneous resistance to at least rifampicin (RMP) and isoniazid (INH) ${ }^{2}$. Patients infected with MDR strains are less likely to be cured from TB particularly if they are co-infected with HIV or suffer from other immuno suppressive diseases ${ }^{3}$.

\section{Corresponding author:}

Wondemagegn Mulu

Department of Medical Microbiology,

Immunology and Parasitology,

Bahir Dar University,

College of Medicine and Health Sciences.

P.O. Box 79, Bahir Dar University, Ethiopia

Tel: +251918706921

Email: Wondem_32@yahoo.com
MDR-TB is associated with a two to four fold period of treatment, psychological problems, economic wastage, poor treatment adherence and consequently treatment failure ${ }^{4,5,6}$. It is also associated with higher case fatality rates $(50-80 \%)$ as a result of drug toxicity 4,5

Globally, $3.5 \%$ of new TB cases and $20.5 \%$ of previously treated cases are estimated to have MDR-TB In developing countries, due to poverty, migration and HIV infection, MDR-TB is associated with spread and persistence in high incidence ${ }^{4,5,6}$. Despite the lack of comprehensive surveillance data from Africa, MDRTB has been recognized as an emerging public health TB has been recognized as an emerging public health
concern. In South Africa, clusters of MDR-TB cases concern. In South Africa, clusters of MDR-TB cases
have been documented in institutional and community settings among HIV-infected patients ${ }^{8}$.

Ethiopia is among the 27 countries with the highest TB burden in the world ${ }^{7}$. The annual TB incidence and prevalence of Ethiopia is estimated to be 247 and 470 cases per 100,000 in $2013^{\circ}$. These days, drug resistant TB has become a common problem and challenge in Ethiopia ${ }^{7}$. Drug resistant TB is estimated as $1.6 \%$ and $12 \%$ among new and previously treated TB cases, respectively ${ }^{7}$.

Factors such as inadequate chemotherapy, poor drug quality, poor adherence to treatment, treatment failure, prior treatment, cavity pulmonary TB, HIV infection and diabetes accounted for the development of drug resistance in $\mathrm{TB}^{10,11}$. Of these, the most powerful predictor for the presence of MDR-TB is a previous history of treatment of $\mathrm{TB}^{10}$. Many new cases of MDRTB develop due to error in TB management such as the use of a single drug to treat TB, the addition of a single drug to a failing regimen, the failure to identify pre-existing resistance, the initiation of an inadequate regimen using first line anti-TB drugs ${ }^{10,11}$. Variations in bioavailability of anti-TB drugs predispose the patient to the development of MDR-TB ${ }^{10,11}$.

Other major factors significantly contributing to the higher complexity of the treatment of MDR-TB is non- adherence to prescribed treatment ${ }^{12}$. Psychiatric illness, alcohol consumption, and travel to different places, symptom relief, adverse drug reactions, drug addiction, homelessness and inability to afford treatment do predict non-adherence to treatment. Poor compliance with treatment is also an important factor in the development of acquired drug resistance ${ }^{10,12,13}$.

Previous studies done in Ethiopia, reported that being male, prior exposure to anti-TB treatment, non-adherence for first line anti-TB treatment, drug side effects during first line treatment, treatment not directly observed with a health worker and interruption of treatment for at least a day were factors significantly associated with MDR-TB ${ }^{14,15}$

It is known that epidemiologic information on risk factors of MDR-TB is important for prevention and control of the spread of the disease in countries where drug resistance is a major threat. However, there is scarcity of information in the study area and at large to our country. Thus, the aim of this study was to determine the potential risk factors for MDR-TB patients among presumptive MDR-TB patients in the Amhara National Regional State (ANRS), Ethiopia.
Methods

tudy design, period and setting

Unmatched case - control study was conducted from May 2013 to January 2014 in ANRS. The State of Amhara is the second largest region of Ethiopia that has an area of $157347 \mathrm{sq} \cdot \mathrm{km}^{16}$. It is located in the north western and north central part of Ethiopia. According to the 2007 census, the region's population was 17 $221976^{16}$. The region is divided into 11 administrative zones with 151 Woredas. Out of these, 128 are rural and 23 are town administration. ANRS has over 500 governmental and private health institutions that provide TB microscopy and directly observed treatment for short course (DOTS) centers ${ }^{14,16}$. Currently, Gondar University specialized and Borumeda Hospital are the only MDR-TB treatment initiation centers in the region. Data on risk factors was collected from MDR and non MDR-TB patients who had follow up in the above MDR-TB treatment initiation centers of the region.

\section{Sample size determination and sampling}

The sample size for cases and controls was calculated using Epi Info 6.04 soft-ware by taking a proportion of males among the controls of $50 \%$ and among the cases of $69.5 \% 0^{10}, 5 \%$ significance level, power $(\%$ chance of detecting) of $80 \%$, a case to control ratio of $1: 1$ and a non response rate of $10 \%$. A total of 358 sample size was calculated. However, only 306 (153 cases and153 controls) TB patients volunteered and participated in the study. All confirmed MDR-TB patients and patients with TB but sensitive to both RMP and INH were enrolled conveniently.

\section{Study population and participants}

Study population included all presumptive MDR -TB patients living in ANRS during the study period.

Cases were presumptive MDR-TB patients who were infected with MDR M. Tuberculosis confirmed with molecular line probe assay (LiPA)

Controls were presumptive MDR-TB patients who were infected with $M$. tuberculosis sensitive to both RMP and INH as per the result of LiPA.

\section{Variables}

MDR-TB was the dependent variable where as socio demographic factors, tuberculosis and its treatment related conditions were the independent variables. 
Data collection

Presumptive MDR-TB: Those TB patients who had Drecimens were collected from presumptive MDR-TB any TB treatment failure, symptomatic close contact of patients for Ziehl Neelsen stain and culture in Lowen- confirmed MDR-TB cases, return after relapse, return stein Jensen medium. From smear and culture positive after default and previously treated cases that remain samples, DNA was extracted and resistance to rifampic- smear positive at the end of intensive phase.

in (RMP) and isoniazid (INH) were done molecularly

using line probe assay (LiPA). Using a structured questionnaire data was collected by both face to face patient interviews and patient's clinical record review. Health officers and nurses who were trained about MDR-TB and working at TB treatment initiation center collected the data. The main variables included in the study were age, sex, monthly income, HIV status, category of TB treatment, number of previous TB treatment,s treatment history, alcohol consumption, smoking, history of irregular treatment during intensive and continuous phase, cavitations on chest $\mathrm{x}$-ray, history of close contact with MDR-TB patients, housing condition and site of tuberculosis .

Operational definitions of terms according to WHO

New patients: A case of TB that has never had antiTB treatment

Previously treated: Patients that have received 1 month or more of anti-TB drugs in the past, may have positive or negative bacteriology and may have disease at any anatomical site.

Relapse: A patient declared cured or treatment completed of any form of TB in the past, but who reports back to the health service and is now found to be acid fast bacilli smear positive or culture positive.

Treatment failure: - A patient who is sputum smear or culture positive at 5 months or later during treatment.

Defaulter:- A patient whose treatment was interrupted for 2 consecutive months or more.
Data management and statistical analysi

Data was analyzed using Statistical Package for Socia Sciences (SPSS) version 20 statistical software. Descriptive statistics were computed to get summary values. Association between variables were determined using odds ratio and 95\% CI. Multivariate analysis was run by selecting those variables that appeared to have a P-value of $<0.05$ in the bivariate analysis to control the confounding effect of different variables while assessing the effect of each variable on the likely hood of MDR TB development. P-value of $<0.05$ was considered as statistical significance

\section{Ethical consideration}

Ethical clearance was obtained from the Research and Ethical Review Board of Bahir Dar University. Moreover, all patients gave written informed consent to participate in this study.

\section{Results}

Characteristics of study participants

A total of 153 MDR-TB and equal number of TB patients infected with non MDR strains participated in the study. Of these, $88(57.5 \%)$ and $90(58.8 \%)$ were males in cases and controls, respectively. Eighty four $(54.9 \%)$ of the cases and $81(52.9 \%)$ of the controls were within the age ranges of $26-45$ years. Detail characteristics of the study participants are presented in table 1.

Table.1. Sociodemographic characteristics of MDR-TB cases ( $\mathrm{N}=153)$ and controls $(\mathrm{N}=153)$, ANRS, 2014

\begin{tabular}{|c|c|c|c|}
\hline Variables & $\begin{array}{l}\text { Cases } \\
\text { N (\%) }\end{array}$ & $\begin{array}{l}\text { Controls } \\
\text { N (\%) }\end{array}$ & COR $(95 \% \mathrm{CI})$ \\
\hline \multicolumn{4}{|l|}{ Sex } \\
\hline Male & $88(57.5)$ & $90(58.8)$ & $1.1(0.67-1.66) *$ \\
\hline \multicolumn{4}{|l|}{$\begin{array}{l}\text { Female } \\
\text { Age category (Years) }\end{array}$} \\
\hline A $<25$ & $56(36.6)$ & $43(28.1)$ & $0.8(0.48-1.31) *$ \\
\hline $26-45$ & $84(54.9)$ & $81(52.9)$ & $0.3(0.16-0.74) * *$ \\
\hline \multirow{2}{*}{\multicolumn{4}{|c|}{ Residence }} \\
\hline & & & \\
\hline Urban & $114(74.5)$ & $97(63.4)$ & $0.6(0.36-0.97) * *$ \\
\hline Rural & $39(25.5)$ & $56(36.6)$ & \\
\hline \multicolumn{4}{|l|}{ Marital status } \\
\hline Single & $56(37.2)$ & $53(34.6)$ & 1 \\
\hline Married & $61(39.9)$ & $83(54.3)$ & $0.4(0.18-0.7) * *$ \\
\hline \multirow{2}{*}{\multicolumn{4}{|c|}{ Educational status }} \\
\hline & & & \\
\hline Illiterate & $53(34.6)$ & $55(36)$ & $1.6(0.65-3.68) *$ \\
\hline Up to elementary & $52(34)$ & $61(39.8)$ & $0.8(0.4-1.6) *$ \\
\hline High school & $26(17)$ & $16(10.5)$ & $0.9(0.45-1.87) *$ \\
\hline College $\&$ above & $22(14.4)$ & $21(13.7)$ & \\
\hline \multicolumn{4}{|l|}{ Occupation } \\
\hline Farmer & $39(25.5)$ & $44(28.8)$ & 1 \\
\hline Student & $13(8.5)$ & $17(11.1)$ & $0.9(0.38-2.07) *$ \\
\hline Merchant & $13(8.5)$ & $17(11.1)$ & $0.9(0.38-2.07) *$ \\
\hline House wife & $37(24.2)$ & $29(19)$ & $1.5(0.77-2.86) *$ \\
\hline Employee & $22(14.4)$ & $22(14.4)$ & $1.2(0.56-2.43) *$ \\
\hline Daily laborer & $29(19)$ & $24(15.7)$ & $1.5(0.75-2.9) * *$ \\
\hline \multicolumn{4}{|l|}{ Monthly income (ETB) } \\
\hline Up to 500 & $54(35.3)$ & $47(30.7)$ & $0.2(0.04-0.85 * *$ \\
\hline $501-1500$ & $79(51.6)$ & $80(52.2)$ & $0.4\left(0.09-1.33^{*}\right.$ \\
\hline $1501-2000$ & $10(6.5)$ & $16(10.5)$ & $(0.29-1.12) *$ \\
\hline
\end{tabular}

Tuberculosis related conditions

The majority of participants had pulmonary TB in cases $141(92.2 \%)$ and controls $137(89.5 \%)$. Proportion of AIDS patients were more in cases $30(19.6 \%) \mathrm{com}^{-}$ pared to controls $21(13.7 \%)$. Homeless participants accounted for $12(7.8 \%)$ in MDR-TB patients and 6 $(3.9 \%)$ in controls. Majority of cases (62.1\%) and 54
$(35.3 \%)$ of controls had cavitation on chest x-ray. Of the 153 MDR-TB cases, $44(28.8 \%)$ had history of conact with MDR- TB patients. In the control group, only $22(14.4 \%)$ had history of close contact with MDR-TB patients. Living in a house of mud floor was higher in the MDR-TB cases $(83.7 \%)$ than in the control group $(71.2 \%)$. The percentage of alcohol drinkers was higher among cases $(29.6 \%)$ than controls $(13.1 \%)$ (Table 2). 
Table 2 Tuberculosis disease related conditions in each category (case/control), ANRS, 2014.

\begin{tabular}{|c|c|c|c|c|c|}
\hline Characteristics & $\begin{array}{l}\text { Cases } \\
(\mathrm{N}=153)\end{array}$ & & $\begin{array}{l}\text { Control } \\
(\mathrm{N}=153)\end{array}$ & & COR $(95 \% \mathrm{CI})$ \\
\hline & Number & Percent & Number & $\begin{array}{c}\text { Percent } \\
\end{array}$ & \\
\hline \multicolumn{6}{|l|}{ History of alcohol consumption } \\
\hline Yes & 33 & 21.6 & 20 & 13.1 & $0.6(0.29-0.94)^{* * *}$ \\
\hline No & 120 & 78.4 & 133 & 86.9 & 1 \\
\hline \multicolumn{6}{|l|}{ Living situation } \\
\hline Individually in a home & 25 & 16.3 & 28 & 18.3 & 1 \\
\hline Within family & 116 & 75.8 & 119 & 77.8 & $0.92(0.5-1.67)^{*}$ \\
\hline Homeless /prisoner & 12 & 7.8 & 6 & 3.9 & $2.1(0.75-5.65)^{* *}$ \\
\hline \multicolumn{6}{|l|}{ History of Contact with MDR- TB } \\
\hline Yes & 44 & 28.8 & 22 & 14.4 & $0.4(0.23-0.14) * *$ \\
\hline No & 109 & 71.2 & 131 & 85.6 & 1 \\
\hline \multicolumn{6}{|l|}{ Floor of the house } \\
\hline Mud & 128 & 83.7 & 109 & 71.2 & $2.1(1.19-3.60)^{* *}$ \\
\hline Cement & 25 & 16.3 & 44 & 28.8 & 1 \\
\hline \multicolumn{6}{|l|}{ Have sewer in the home } \\
\hline Yes & 30 & 19.6 & 69 & 45.1 & 1 \\
\hline No & 123 & 80.4 & 84 & 54.9 & $0.3(0.18-0.49)^{* * * *}$ \\
\hline \multicolumn{6}{|l|}{ Number of people in a house } \\
\hline Average (2) & 32 & 20.9 & 32 & 20.9 & 1 \\
\hline Below average $(<2)$ & 31 & 20.3 & 31 & 20.3 & $1.0(0.49-2.03)^{*}$ \\
\hline Above average $(>2)$ & 90 & 58.8 & 90 & 58.8 & $1.0(0.56-1.78) *$ \\
\hline \multicolumn{6}{|l|}{ HIV status } \\
\hline HIV Negative & 110 & 71.9 & 119 & 77.8 & 1 \\
\hline HIV Positive & 13 & 8.5 & 13 & 8.5 & $1.1(0.48-2.44)^{*}$ \\
\hline AIDS & 30 & 19.6 & 21 & 13.7 & $1.5(0.84-2.86)^{*}$ \\
\hline \multicolumn{6}{|l|}{ Site of TB the patient has } \\
\hline Pulmonary & 141 & 92.2 & 137 & 89.5 & $1.4(0.63-3.01) *$ \\
\hline Extra-pulmonary & 12 & 7.8 & 16 & 10.6 & 1 \\
\hline \multicolumn{6}{|l|}{ Had cavitations on chest $\mathrm{X}$-ray } \\
\hline Yes & 95 & 62.1 & 54 & 35.3 & $3.0(1.89-4.83)^{* * *}$ \\
\hline No & 58 & 37.9 & 99 & 64.7 & 1 \\
\hline
\end{tabular}

Key: ANRS (Amhara national Regional State), COR (Crude odds ratio), ${ }^{* * * *}$ P-value $<0.001$, ** P - value $<0.05$, , $\mathrm{P}$-value $>0.0$

Of the 153 MDR-TB cases, $1(0.7 \%)$ was a defaulter, of the cases and controls, respectively. Irregular treat$135(88.2 \%)$ were treatment failure, $14(9.2 \%)$ were ment during intensive phase occurred in $22(14.3 \%)$ relapse and $3(2 \%)$ were new cases. While in the con- of cases and $9(5.9 \%)$ of controls. Moreover, irregutrols, defaulters were $3(2 \%)$, treatment failures were 66 lar treatment during continuous phase occurred in 26 $(43.1 \%)$, relapses were $57(37.3 \%)$ and new cases were $(17 \%)$ of the cases and $13(7.9 \%)$ of the controls. One $26(17 \%)$. Previous treatment for $>2$ times with anti TB hundred twenty nine MDR-TB cases $(86.6 \%)$ and 100 drug were encountered in $121(79.1 \%)$ and $89(58.2 \%) \quad(67.1 \%)$ controls had history of treatment at a health facility (Table 3).

Table 3 Tuberculosis treatment-related conditions in MDR-TB cases and controls ANRS, 2014.

\begin{tabular}{|c|c|c|c|c|c|}
\hline Variables & Cases & Percent & Controls & Percent & COR $(95 \% \mathrm{CI})$ \\
\hline \multicolumn{6}{|l|}{ Treatment history } \\
\hline Previously untreated & 6 & 3.9 & 22 & 14.4 & 1 \\
\hline Previously treated & 147 & 96.1 & 131 & 85.6 & $0.2(0.1-0.62)^{* * *}$ \\
\hline \multicolumn{6}{|l|}{ Category of TB-treatment } \\
\hline Defaulters & 1 & 0.7 & 3 & 2 & $2.9(0.22-37.4) *$ \\
\hline Treatment failure & 135 & 88.2 & 66 & 43.1 & $17.7(5.1-60) * * *$ \\
\hline Relapse & 14 & 9.2 & 57 & 37.3 & $2.1(0.56-8.05) *$ \\
\hline New case & 3 & 2 & 26 & 17 & \\
\hline \multicolumn{6}{|l|}{ Number of previous treatment } \\
\hline $0-1$ & 32 & 20.9 & 64 & 41.8 & 1 \\
\hline 2 and above & 121 & 79.1 & 89 & 58.2 & $2.6(1.6-4.39)^{* * *}$ \\
\hline \multicolumn{6}{|l|}{ Place of TB treatment } \\
\hline In home & 20 & 13.4 & 49 & 32.9 & $0.3(0.19-0.59) * * *$ \\
\hline In health facility & 129 & 86.6 & 100 & 67.1 & 1 \\
\hline \multicolumn{6}{|c|}{$\begin{array}{l}\text { Private TB diagnostic \& treatment } \\
\text { center }\end{array}$} \\
\hline Yes & 41 & 26.8 & 45 & 29.4 & $1.1(0.7-1.9)^{*}$ \\
\hline No & 112 & 73.2 & 108 & 70.6 & 1 \\
\hline \multicolumn{6}{|c|}{$\begin{array}{l}\text { Irregular treatment during intensive } \\
\text { phase }\end{array}$} \\
\hline Yes & 22 & 14.4 & 9 & 5.9 & $0.4(0.17-0.84)^{* *}$ \\
\hline No & 131 & 85.6 & 143 & 94.1 & 1 \\
\hline \multicolumn{6}{|c|}{ Irregular treatment during continuous } \\
\hline \multicolumn{6}{|c|}{ phase } \\
\hline Yes & 26 & 17 & 13 & 7.9 & $0.5(0.23-0.93)^{* *}$ \\
\hline No & 127 & 83 & 139 & 92.1 & 1 \\
\hline \multicolumn{6}{|c|}{$\begin{array}{l}\text { Previous treatment with insufficient } \\
\text { duration }\end{array}$} \\
\hline Yes & 10 & 6.5 & 11 & 7.2 & $1.0(0.42-2.38)^{*}$ \\
\hline No & 143 & 93.5 & 142 & 92.8 & 1 \\
\hline
\end{tabular}

key: ANRS: Amhara National Regional State, COR (Crude Odds ratio), ${ }^{1}$ (Reference category)

***P-value $<0.001,{ }^{* *}$ P-value $<0.05$, * P-value $>0.05$

\section{Logistic regression analysis} 列 13.5 times more likely to develop MDR-TB ficantly associated with previous history than those who completed the course of TB treatment. TB treatment failure ( $\mathrm{AOR}=13.5, \mathrm{CI}=2.69-70)$, Moreover, those $\mathrm{TB}$ patients who had $>2$ times previcavitation on chest $\mathrm{x}$-ray $(\mathrm{AOR}=1.9, \mathrm{CI}=1.1-3.38), \quad$ ous anti $-\mathrm{TB}$ treatment were 1.9 times more likely to young age $(\mathrm{AOR}=2.9,95 \% \mathrm{CI}=1.07-7.68)$, low develop MDR-TB compared to those who had not. $\mathrm{TB}$ monthly income $(\mathrm{AOR}=1.1$, CI $0.34-0.47)$, history patients who had cavitations on chest $\mathrm{x}$-ray were 1.9 of contact with MDR-TB patients $(\mathrm{AOR}=1.4, \mathrm{CI}=$ times more likely to have MDR-TB than those who had $0.19-0.39)$ and alcohol consumption ( $\mathrm{AOR}=1.5, \mathrm{CI}=$ not. Patients whose ages were below 26 years old were $0.2-0.98$ ) (Table 4).
2.9 times more likely to have MDR-TB than those TB patients with age group of 26 years and above (Table 4). 


\begin{tabular}{|c|c|c|c|c|c|}
\hline Characteristics & Case & Control & COR & AOR & P-value \\
\hline \multicolumn{6}{|l|}{ Age of participants } \\
\hline$\leq 25$ & 56 & 43 & $0.8(0.48-1.31)$ & $2.9(1.07-7.68)$ & 0.036 \\
\hline $26-45$ & 84 & 81 & $0.3(0.16-0.74)$ & $2.2(0.89-5.49)$ & 0.09 \\
\hline$\geq 46$ & 13 & 29 & & & \\
\hline \multicolumn{6}{|l|}{ Residence } \\
\hline Urban & 114 & 97 & $0.6(0.36-0.97)$ & $0.5(0.25-0.92)$ & 0.03 \\
\hline Rural & 39 & 56 & 1 & & \\
\hline \multicolumn{6}{|l|}{ Marital status } \\
\hline Single & 56 & 53 & 1 & 1 & \\
\hline Married & 61 & 83 & $1.9(0.98-3.9)$ & $1.16(0.52-2.58)$ & 0.04 \\
\hline Divorced/widowed & 35 & 17 & $0.7(0.42-1.15)$ & $2.4(0.89-6.57)$ & 0.08 \\
\hline \multicolumn{6}{|l|}{ Monthly income ( ETB) } \\
\hline$\leq 500$ & 54 & 47 & $0.2(0.04-0.85)$ & $0.1(0.34-1.47)$ & 0.003 \\
\hline 501-1500 & 79 & 80 & $0.4(0.09-1.33$ & $0.2(0.03-0.79)$ & 0.24 \\
\hline $1501-2000$ & 10 & 16 & $(0.29-1.12)$ & $0.2(0.03-0.75)$ & 0.02 \\
\hline$>2001$ & 10 & 3 & 1 & & \\
\hline \multicolumn{6}{|l|}{ Alcohol consumption } \\
\hline Yes & 33 & 20 & $0.6(0.29-1.00)$ & $0.5(0.2-0.98)$ & 0.04 \\
\hline No & 120 & 133 & & 1 & \\
\hline \multicolumn{6}{|l|}{ Contact with MDR-TB patients } \\
\hline Yes & 44 & 22 & $0.4(0.24-0.74)$ & $0.4(0.19-0.39)$ & 0.012 \\
\hline № & 109 & 131 & & 1 & \\
\hline \multicolumn{6}{|l|}{ Floor of the living house } \\
\hline Mud & 128 & 108 & $2.1(1.19-3.6)$ & $2.1(0.93-4.4)$ & 0.08 \\
\hline Cement/Other & 25 & 44 & & & \\
\hline \multicolumn{6}{|l|}{ Had cavitations on chest X-ray } \\
\hline Yes & 95 & 53 & $0.3(0.21-0.53)$ & $1.9(1.07-3.38)$ & 0.03 \\
\hline № & 58 & 98 & & & \\
\hline \multicolumn{6}{|l|}{ Category of TB treatment } \\
\hline Defaulters & 1 & 3 & $2.9(0.22-37.3)$ & $2.7(0.49-14.9)$ & 0.26 \\
\hline Treatment failure & 135 & 66 & $17.7(5.2-60.7)$ & $13.5(2.69-70)$ & 0.002 \\
\hline Relapse & 14 & 57 & $2.1(0.56-8.1)$ & $5.2(0.31-88)$ & 0.25 \\
\hline New case & 3 & 26 & & 1 & \\
\hline \multicolumn{6}{|l|}{ Number of previous treatment } \\
\hline $0-1$ & 32 & 62 & 1 & 1 & \\
\hline 2 and above & 120 & 88 & $0.2(0.12-0.48)$ & $1.9(0.95-3.61)$ & 0.07 \\
\hline \multicolumn{6}{|l|}{ Place of TB treatment } \\
\hline Home & 21 & 49 & 1 & 1 & \\
\hline Health facility & 129 & 100 & $0.3(0.19-0.59)$ & $1.8(0.9-3.49)$ & 0.09 \\
\hline \multicolumn{6}{|c|}{ Irregular treatment during intensive phase } \\
\hline Yes & 22 & 9 & $0.4(0.17-0.84)$ & $1.1(0.25-4.24)$ & 0.97 \\
\hline No & 131 & 143 & & & \\
\hline \multicolumn{6}{|c|}{ Irregular treatment during continuation phase } \\
\hline Yes & 26 & 17 & $0.5(0.23-0.93)$ & $0.8(0.35-2.23)$ & 0.89 \\
\hline No & 127 & 83 & & & \\
\hline
\end{tabular}

Key: ANRS (Amhara National Regional State), COR (Crude odds ratio), AOR (Adjusted odds ratio)

\section{Discussion} having MDR-TB. This conforms to other studies conto determine the risk factors for MDR-TB infection ducted in different parts of the world ${ }^{14,17-21}$. Similarly, among presumptive MDR-TB patients. History of TB a nationwide anti-TB drug resistance survey conducted in Ethiopia stated that $11.8 \%$ of the MDR-TB cases In this study, young age presumptive MDR-TB pahad history of anti-TB therapy while $1.6 \%$ were newtreatment failure and MDR-TB might be related to unsatisfactory compliance by patients or clinicians, lack of supervision of treatment, improper drug regimens and inadequate or irregular drug supply that may potentiate drug resistance ${ }^{14,17-21}$. Furthermore, those TB patients who had history of $>2$ times anti TB treatment were 1.9 times more likely to be at risk of developing MDRTB. This is in accordance with study done in Ethiopia ${ }^{14}$ and Pakistan ${ }^{2}$. The association between increased number of previous TB treatments and MDR-TB might be due to poor adherence of patients that may potentiate secondary drug resistance.

Data on the relationship between cavitations on chest $x$-ray finding and MDR-TB is insufficient in the literlung cavities are a risk factor for MDR-TB. This finding was in agreement with studies conducted in Brazili23,24. The association between lung cavities and MDR-TB was attributable to existence of a higher probability of first step resistant fast multiplication to up to 108 or 109 bacilli cavities, due to the high level of oxygenation and to the protection granted to the bacilli by thick walls which keep drugs from reaching adequate inhibitory concentrations. Concomitantly with inadequate treatments, cavities are a favorable environment for the development of MDR-TB 23,24 .

An association between history of close contact with MDR-TB patients and subsequent MDR-TB cases in this study conforms to other studies ${ }^{18,19,25}$. The association between history of close contact with MDR-TB patients and MDR-TB strain would be attributable to acquiring of primary drug resistant bacteria from the patient.

Many studies reported that poor treatment adherence and irregular treatment were the strongest risk factors for development of MDR-TB ${ }^{14,23,26}$. This study also revealed that the rate of MDR-TB was higher among patients who did not adhere to the proper treatment during intensive and continuous phase. This might be associated with increased bacterial death and growth cycles, giving more opportunities for individual mutations of different independent genes to accumulate ${ }^{27}$. some concrete steps to be taken to combat this disease in order to save the economically productive population. This finding is in accordance with other reports in Ethiopia ${ }^{2,14}$. To the contrary, a study in other setting stated that MDR-TB was more prevalent among older age group ${ }^{20}$. Moreover, regarding socio-economic factors, majority of MDR-TB patients were from low socioeconomic status ${ }^{2,28,29}$. This might be due to poor compliance with TB treatment often due to poor living and housing condition and limited access to medical treatment and health care services which might facilitate the spread of infectious bacilli. Hence, these lower socioeconomic groups should be the highest priority in MDR-TB prevention and control efforts.

In the present study, alcohol consumption was also one of the risk factor for the development of MDR-TB. It might be associated with its significant role for default and failure rate among new TB cases. Hence, it increases the rate of MDR-TB cases. In another studies also cohol consumption was frequently reported as one of the risk factors for MDR $\mathrm{TB}^{23}$ and was also a risk factor for default ${ }^{24}$.

Similar to previous studies, HIV status had no significant association with MDR-TB $14,23,30$. In addition, in France ${ }^{31}$ and Ukraine ${ }^{32}$ being HIV positive was associated with primary MDR-TB but it was not associated with secondary MDR-TB in France ${ }^{31}$. This is because HIV is one risk factor for drug susceptible TB, which a study in South Africa ${ }^{33}$ showed that in retreated patients, HIV had no significant association with MDRTB. Although, we did not differentiate being HIV positive or treatment for $\mathrm{TB}$ which came first, greater than $95 \%$ of the MDR-TB study participants in our study were patients who had a history of TB treatment and the result could have been different if all study participants were primary MDR-TB cases rather than secondary MDR-TB cases.

The major strength of this survey was inclusion of presumptive MDR-TB patients living in all parts of the Amhara Region and selecting the cases and controls based on the result of molecular technique, line probe assay. However, this study could not differentiate whether MDR-TB cases were primarily MDR-TB or secondary MDR-TB. is associated to immune system suppression. Moreover, 

tors for MDR-TB patients that would provide base line information for high TB burden countries like Ethiopia. In this survey, previous TB treatment failure, having cavitations on chest $\mathrm{x}$-ray, contact with MDR-TB patients and low socioeconomic status were the major predictors for having MDR-TB. Therefore, strict adherence to DOTS, basic TB infection control practices, appropriate management of TB patients and advice on the value of nutrients are imperative to control the spreading of MDR-TB

\section{Competing interests}

The authors declare that they have no competing interests.

\section{Author's contribution}

MW conceived and designed the study, collected and analyzed data and wrote the manuscript, MD designed the study, was involved in data collection, revised the questionnaire and the manuscript. YM revised the questionnaires and manuscript and AA revised the manuscript, $A B$ designed the study, reviewed the questionnaire and critically revised the manuscript. All authors read and approved the manuscript.

\section{Author's information}

MW is an assistant professor of Medical Microbiology at College of Medicine and Health Sciences, Bahir Da University. MD is a Lecturer at College of Medicine and Health Sciences, Bahir Dar University in Medical Microbiology. YM is an assistant professor of Medical Parasitology at College of Medicine and Health Sciences, Bahir Dar University. AA is a Mycobacteriologist in Bahir Dar Regional Laboratory Research Center, AB is an Associate professor of Medical Microbiology, department head of Microbiology, Immunology and Parasitology at College of Medicine and Health Sciences, Bahir Dar University.

\section{Acknowledgments}

This study was funded by the College of Medicine and Health Sciences, Bahir Dar University. Our greatest thanks goes to Gondar University specialized, Borumeda and Felege hiwot referral Hospital and other TB treatment centers of the region for supporting us during data collection. We would also like to thank the study participants.

\section{References}

Zerer culosis. BMC Infect Dis 2008; 8:1-15.

2. Wahab F, Ashraf S, Khan N, Anwar R, Afridi MZ Risk factors for multidrug resistant tuberculosis in patients at tertiary care Hospital, Peshawar. J Coll Phys Surg Pak 2009; 19: 162 -164.

3. Marahatta SB. Multidrug resistant tuberculosis burden and risk factors: An update. Kathmandu University Med J; 2010 8:116 -125.

4. Faustini A, Hall JA, Perucci CA. Risk factors for multidrug resistant tuberculosis in Europe: a systematic review. Thorax 2006; 61:158- PubMed ;163.

5. Casal M, Vaquerom H. Rinder H. A Case-Control study for multidrug-resistant tuberculosis: Risk factor in four European Countries. Microb Drug Resist 2005; 11: $62-67$

6. Franke M, Appleton SC, Bayona J et al . Risk factors and mortality associated with default from multid-

rug-resistant tuberculosis treatment. Clin Infect Dis 2008; 15: 46: 1844-1851

7. World Health Organization. Global tuberculosis report. Geneva. WHO 2014. http://www.who.int/tb/ data.

8. Weyer K, Brand J, Lancaster J,Levin J, vanderwalt M. Determinants of multidrug-resistant tuberculosis in South Africa: results from anational survey. SAfr Med J 2007;97:1120-1128.

9. Biadglegne F, Sack U, Rodlof AC. Multidrug-resistant tuberculosis in Ethiopia: efforts to expand diagnostic services, treatment and care. Antimicrobial Resistance and Infection Control 2014, 3:31

10. Akl MA, Mahalli AA. Drug resistant tuberculosis: Risk factors and resources- utilization at a chest disease clinic, Alexandria, Egypt. J AM Sci 2012; 8:107-112.

11. Caminero JA. Multidrug-resistant tuberculosis: epidemiology, risk factors and case finding. Int J Tuber Lung Dis 14 (4): 382 - 390.

12. Farley JE, Ram M, Pan W et al. Outcomes of multi-drug resistant tuberculosis (MDR-TB) among a cohort of South African patients with high HIV Prevalence. PLoS ONE 2011; 6:1-6.

13. Baghaei P, Tabarsi P, Chitsaz E. Risk factors associated with multidrug-resistant tuberculosis. Tanaffos 2009, 8: 17-21.

14. Hirpa S, Medihn G, Girma B et al. Determinants of multi drug- resistant tuberculosis in patients who underwent first-line treatment Addis Ababa: a case-control study. BMC Public Health 2013; 13: 2 - 9 PubMed .

15. Yimer S, Bjune G, Alene G. Diagnostic and treat- ment delay among pulmonary tuberculosis patients in 25. Telles MA, Ferrazoli L, Waldman EA. A study Ethiopia: a cross sectional study. BMC Infect Dis 2005; $5 \cdot 1-7$

16. Central Statistical agency. Ethiopia Demographic and health Survey. CSA 2011; avaialbale at www.unicef. org/ethiopia/ET_2011_EDHS.pdf.

17. Amhara National Regional State Health Bureau (ANRSHB): 5th National Tuberculosis Research Conference. 2009

8. Ricks PM, Mavhunga F, Modi S, etal. Characteristic of multidrug-resistant tuberculosis in Nambia. BMC Infect Dis 2012; 12: 2 - PubMed ; 8 .

19. Velasquez GE, Yagui M, Cegielski P, Asencious L, Bayona J. Targeted drug -resistant testing strategy for multidrug- resistant tuberculosis detection. Emerg Infect Dis 2011; 17: 432-440 PubMed

20. Caminro JA. Likely hood of generating MDR-TB and XDR-TB under adequate national Tuberculosis control programme implementation. Int I Tuberc Lung Dis 2008; 12: 869 - 877 .

21. Merza MA, Farina P, Tabarsi P, Khazampour M, Masjedi MR, Velayati AA. Antituberculosis drug resistance and associated risk factors in a tertiary level TB centre in Iran: a retrospective analysis. I Infect Dev Ctries 2011: 5 : 511-519

22. Dooley KE, Lahlou Q, Ghali I et al. Risk factor for tuberculosis treatment failure, default, or relaps and outcomes of retreatment in Morocco. BMC Public Health 2011; 11: 1-7 PubMed .

23. Mesfin MM, Tasew W'T, Richard JM. The quality of tuberculosis diagnosis in districts of Tigray region of northern Ethiopia. Ethiop J Health Dev 2005;19:14-20 24. Barroso EC, Salaminota RM, Santos RO, Sousa AO, Barroso JB, Rodrigues JL. Risk factors for acquired multidrug- resistant tuberculosis. J pnumol 2003; 29: 8997 PubMed .
. the city of Santos, Saopaulo, Brazil. Men Inst Oswaldo cruz, Riodejaneiro. 2012; 107: 760-766.

26. Jurcev-Savicevic A, Mulic R, Ban B, Kozul K, Bacun-Ivcek L, valic J, et al. Risk factors for pulmonary BMC Public Health 2013; 13: 1-8 PubMed.

27. Lomtadze N, Aspindzelashivili R, Janjgava M, et al. Prevalence and risk factors for multidrug-resistant tuberculosis in Georgia. A population based study. 2006. 28. Daniel O, Osman E. Prevalence and risk factors associated with drug resistant tuberculosis in south west Nigeria. Asia Pac J Trop Med 2011; 148-151.

29. Chen S, Huai P, Wang X et al. Risk factors for multidrug resistance among previously treated patient with tuberculosis in eastern china: a case-control study. Int $J$ Infect Dis 2013; 17: e1116-e1120.

30. Flora Ms, Amin MN, karim MR et al. Risk factors of multidrug resistant tuberculosis in bangeladeshi population: a case control study. Bangladesh med ResCounc Bull 2013; 39: 34 - 41.

11. Akksilp S, Wattanaamornkiat W, Kittikraisak W et l. Multidrug resistant TB and HIV in Thailand: overlapping, but not independently associated, risk factors. Southeast Asian J Trop Med Public Health 2009; 40: 1000 $-1014$

32. Schwoebel V, Decludt D, DeBenoist AC et al. Multidrug resistant tuberculosis in France 1992-4: two casecontrol studies. BMJ 1998; 317: 630 - PubMed ; 631.

33. Alcorn K: HIV a major risk factor for MDR TB in 34. Naidoo P, Peltzer K Louw J, Matseke G, Mchunu G, Tutshana B. Predictors of tuberculosis (TB) and antiretroviral (ARV) medication non-adherence in public primary care patients in South Africa: a cross sectional study. BMC Public Health 2013; 13 (396): 1-10. tuberculosis in Croatia: a matched case-control study. Ukraine. AIDS map HIV \& AIDS news. 2007. 